\title{
MATERIALS RESEARCH POLICY
}

\author{
How The Federal Government Is Supporting
}

'The Most Important Field Of Science In The U.S. Today'

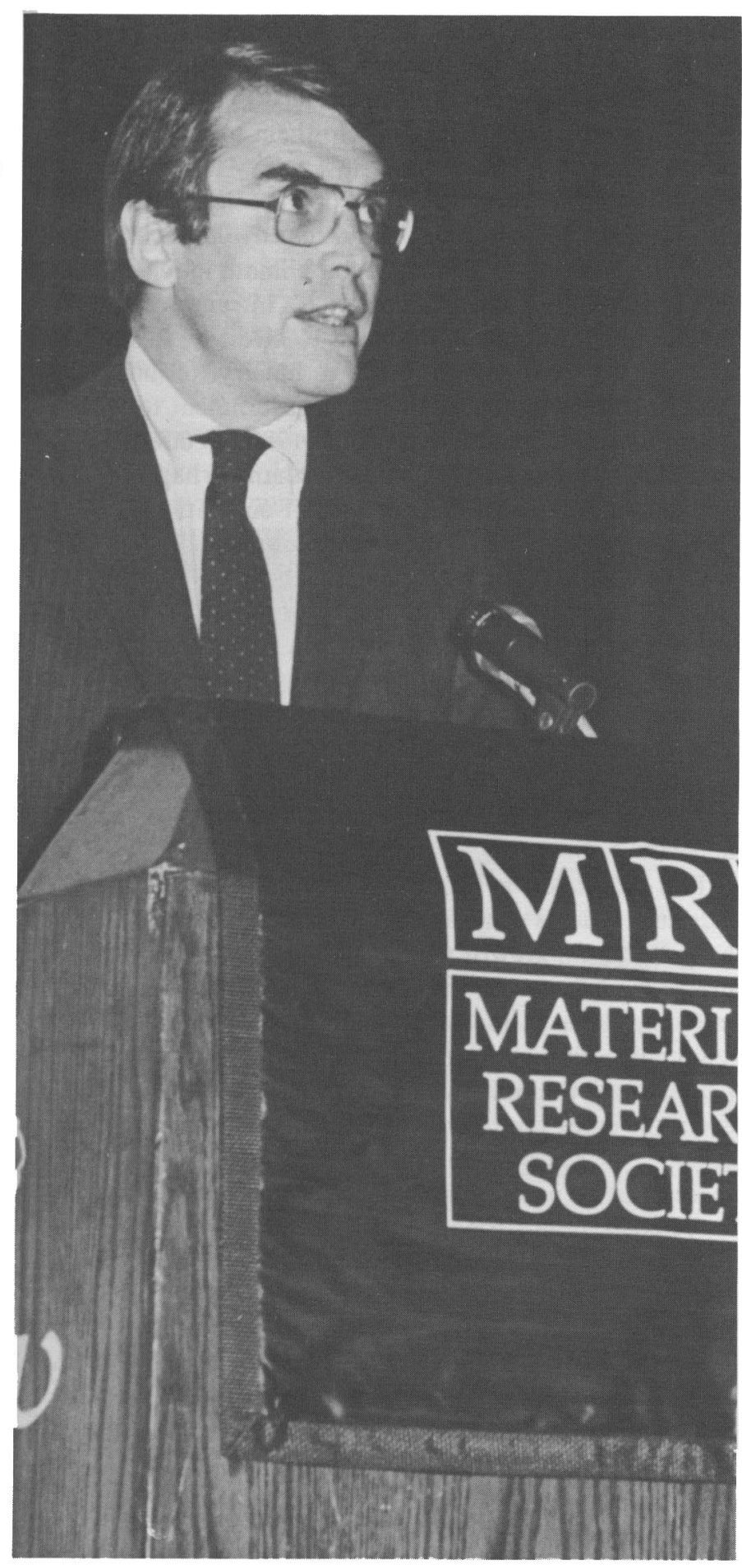

GEORGE KEYWORTH

\section{BY GEORGE A. KEYWORTH II}

Science Advisor to the President Director,

Office of Science And Technology Policy

I still like to think of myself as a physicist, even if I am working in that state of suspended animation known as "working in Washington." So please recognize that l'm overcoming all those years of assuming only physics really counts when I say that materials research may well be the most important field of science in the U.S. today. The reason is actually simple: Not only are materials scientists needed for the success of virtually all the new technologies important to our industrial progress, but many of you have been years ahead of the rest of us in anticipating the benefits of multidisciplinary approaches to frontier research.

To explain the importance of that observation, let me recount an experience I had last month when leaders of a National Academy panel on the use of computers in design and manufacturing came to my office to present the results of their review. As frequently happens these days, the talk soon shifted to problems of universities, industry, and education-especially engineering education. Since we ran out of time long before we ran out of discussion, we met again a few weeks later-this time inviting in leaders and officials of the National Science Foundation, too.

We had a single item on our agenda: It was how universities could do a better job of preparing today's students to function in tomorrow's industrial environment. We all recognized that students take-and master-an impressive array of specialized courses. But, at the same time, very few learn enough about how people in industry work-or about how they succeed. Students are educated in an abstract world, and then most of them are expected to jump right into a practical profession.

I should emphasize that we weren't looking for people to blame for this situation, and in particular the universities came in for more commiseration than anything else. After all, in light of the demands on them, they're already hardpressed to maintain existing programs; few universities are in a position to undertake major reforms on their own. They need help-and justifiable help-from the beneficiaries of their efforts - the eventual employers of those students and the users of new knowledge-industry and government.

\section{Industry/University Cooperative Models}

As one outcome of that meeting, I asked the National Science Foundation to work-particularly with the 
engineering community - to identify promising

university/industry cooperative models for support. One of the more exciting approaches already proposed is for oncampus "engineering centers" in which undergraduate and graduate students can work with faculty on scaled-down industrial research problems in design and manufacturing. Now here's where we come back to my initial observation about materials research. We think there are already some interesting university models to build on-the materials research laboratories. The idea of having a place a campus-communal turf, if you will-to which different kinds of scientists can come together to work on broad problems is worth exploring more fully.

This team approach on the campus could give students a more intense and realistic educational experience than they get now; it would also provide a way to broaden the scope of university engineering research, even to expose mechanical engineers to the sophistication of surface science. After all, wherever these centers may wind up on a campus, it's hard to imagine very many kinds of technical development in the future that won't have to involve materials scientists along with other researchers. As you know better than I do, new materials and new applications of materials are more and more central to emerging technologies.

Just two weeks ago the governing council of the National Academy of Engineering offered to help develop this idea for implementation. In the near future the NAE will circulate an outline of the proposed approach and convene a meeting of national engineering leaders to consider how it could be refined and put into practice.

Let me stress my belief that right now-late 1983-is a critical time to press for major improvements in technical education at all levels, and especially in universities. Partly as a result of the new competitive era we've entered, both industry and the public are responsive to the need to commit resources to improving American education. Will that mood and enthusiasm continue if we don't do something soon? I don't know-but I know I don't want to take a chance on losing this momentum. For that reason I urge you, just as I urged the members of the Academy of Engineering, to make education a high priority, to push for some bold steps now.

Let's reflect for a moment on that new competition that $I$ mentioned-and on how this nation is going to have to respond to it. In spite of our strong free enterprise system and our historic appetite for competing with one another, we seem to have been caught by surprise by the growing foreign challenges to U.S. industry in fields-especially technical fields-we've been used to dominating.

Our self-esteem suffered, and I think it reached its low point a year or so ago when there was great moaning throughout the country about how the Japanese were overwhelming us and how we had to take drastic steps to protect our battered American industries and American workers. That was, to say the least, a gross overreaction. That rapid embrace of defeatism was hardly what we would have expected from an industrial community that was born in competition and which had led the world for decades. And, in fact, that attitude has now started to fade.
Happily, we've now been largely restored to our senses. We see much more clearly today that while many of our industries are being challenged by foreign competition, they're hardly being beaten. And, unlike those panicky times a few years ago, when many of those challenged industries were turning to Washington for help, most of them today have rekindled that competitive spirit and are charging aggressively back into the marketplace. They've concluded that the best way to win the race is to run faster, not to try to get the other runner disqualified.

\section{Pressure on Government to Choose Wisely}

Well, how can Washington help them to run faster? As Science Advisor to the President, I follow two general guidelines in my own evaluation of the role government should play. First, we must be responsive to technological opportunities and must maintain a climate in which they can be capitalized on. Government won't intrude when the private sector has enough interest to invest on its own, but we won't let ripe, relevant fields go hungry for long, either. This puts considerable pressure on government to choose wisely, because we fully expect the 1980 s to offer us more advances in science and technology than perhaps any decade in history. As the ultimate trustee of our national technological strength, government must be aware of and responsive to the opportunities that these advances provide.

Why? Because our economic future and the whole free world's security are so clearly tied to U.S. strength in science and its application, technology. We recognize our responsibility to use U.S. science resources to advance knowledge broadly, and we also recognize the advantage to our own economy of being first to develop new knowledge and first to put it to use for economic growth and national defense.

This rationale was an important element in the Administration's commitment to strong growth for U.S. basic research, growth that exceeds anything we've seen for many, many years. This fiscal year we're seeing an increase in federal support for basic research in the physical sciences and engineering of more than 15 percent, and more than 28 percent over the past two years. And the materials sciences are right up at the top of the list. For example, materials science programs at the National Science Foundation are up more than 20 percent this year over the year before, and we're continuing strong support in other agencies, as well, such as the Department of Energy. And all of this, as you well know, comes at a time of strong pressure to reduce federal spending.

But support for basic research doesn't constitute the whole of federal science policy-not by a long shot. A strong component of our determination to strengthen basic research stems directly from our expectation that new knowledge and well-trained people are the base for our future economic growth and national security.

Perhaps our foremost concern is for the continuing development of technical talent-the scientists and engineers who are needed to keep the remarkable twentieth-century scientific revolution going. Our emphasis on engineering 
education, for example, reflects this larger issue: the likelihood that our rate of economic growth will be strongly dependent on the supply-and on the quality-of technically trained people of all kinds.

Very early in the Reagan Administration the President made it clear that we had to strengthen that national scientific and technical personnel base. Our first priority was for immediate emphasis on training people in those areas of science and technology likely to have the greatest impact on both industrial growth and national defense; that is, we had to address the immediate problem of enough professional scientists and engineers.

\section{Preferential Growth in Research Support}

That meant concentrating on university training, and we realized we could quickly capitalize on an existing mechanism that we know works well-the participation of graduate students in research projects as an integral part of their schooling. That unique dual function of universities explains our tremendous emphasis on academic research. Over the next few years we expect to see continuing strong growth, even preferential growth, in federal support for university research. The reason is that no other research institutions give as much return on investment as universities in the long term-not federal labs, not non-profit organizations, not industry. No other institutions produce both knowledge and people.

But we also know that some pressing personnel problems won't be adequately addressed this way. True, we've got a good means of increasing the quality of people who get their training in the laboratory. And we see a promising path for adding more multidisciplinary project training. But we're far less able to train people in the classroom, and that problem haunts us from the universities right down to elementary schools.

As we all know, the universities are hurt by critical faculty shortages in fields like electrical engineering and computer science. These shortages make it difficult to keep pace with the increasing student demand for training, and they compromise our universities' ability to prepare their students for the rapidly changing technical environment they'll face in the balance of this century. One thing we know: The industrial world will not be conducted on a business-as-usual basis, and the firms-and countries-that emerge in strong economic position will be those that are best at using new technologies to create new industries and to modernize old ones.

Here's an example. The microelectronics revolution is only

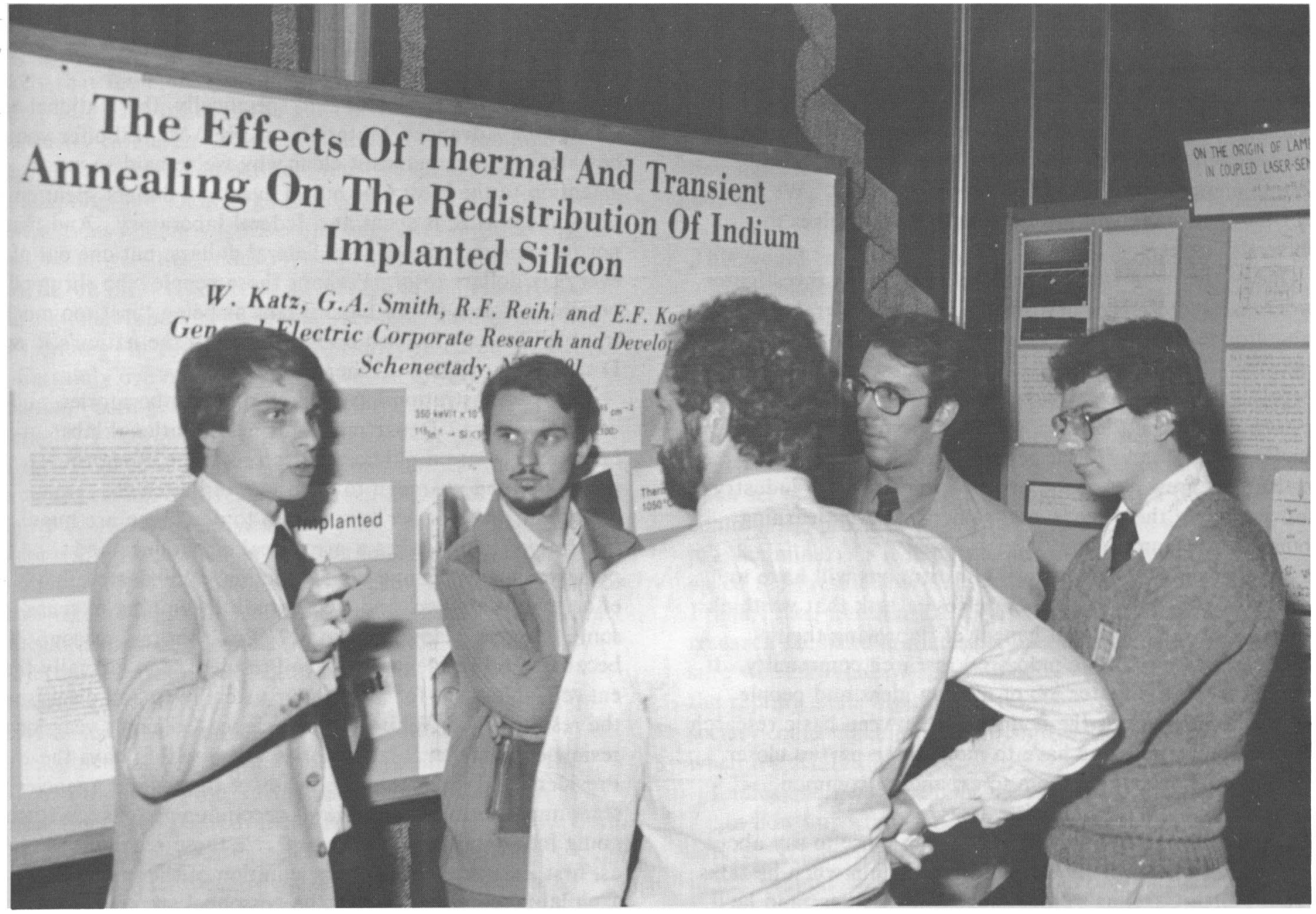

POSTER SESSION sparks lively exchange 
going to speed up. We can envision today's engineering students, some time soon in their careers, having the computing capacity of, say, a CRAY-2 sitting on their desks-or even in their briefcases. Such computing power would give engineers almost unimaginable new flexibility and creativity in the design process that's at the heart of their profession. It really calls for entirely new approaches to problem-solving, and there will be a tremendous premium on knowing how to use that capacity.

Will tomorrow's technical work force be prepared to take advantage of those and other revolutionary tools? In light of our current university faculty shortages, I wonder. Changes like these advances in computers will have immense impact on technological development-and they'll pose the kinds of problems we can anticipate and should be doing something about now.

Well, how do you plan for something like this? One direct step we took this past year was to establish a new program of Presidential Young Investigator Awards. All indications so far are that these flexible research awards will attract and retain outstanding young PhD's for university research. These are some of the best people who might otherwise choose non-teaching careers in industry. Each year we'll make 200 new five-year awards, and after five years we'll have a steady-state of 1,000 young faculty being supported.

These Presidential Investigators will be eligible for research support at up to $\$ 100,000$ per year, with the funding shared by the federal government and industry. At the completion of their five years these faculty should be able to compete well for other research support. We hope by then that many will have committed themselves to university careers.

One of the important elements of that young investigator program-and of other new university- and federal laboratory-based research activities-is the involvement of industry. Today's mutual isolation of these institutions is largely a consequence of our country's rapid economic growth over recent decades. With plenty of government funding available for basic research, scientists and their institutions grew out of the habit of working with industry, understanding their needs, and sometimes even learning some science from them.

For that reason the sponsoring institutions will have to raise that industry money themselves - a task that we think will provide the additional benefit of improving their communication with the industrial research community. If we expect to do a better job of moving ideas and people back and forth across the boundaries between basic research and its applications, we have to move those parties closer together and encourage them to expand on common interests.

I'm sure Don Beilman will have much more to say about the benefits of university/industry interaction when he talks about North Carolina's Microelectronics Center-and he'll point out as well how that state government forecasts handsome returns on wise investments in research, development, and education.

\section{The Alarming Shortage of Teachers}

Now we also face a larger, less tractable problem than university education. That's the alarming shortage of good-or even qualified-secondary school science and math teachers. These are the people who are really on the front lines. Because of highly decentralized and locally independent control of U.S. pre-college education, the only lasting solution to these shortages will be for the public to decide to restore school teaching to a profession of importance. Among other things, that means compensation that would at least permit someone to weigh the alternatives of working as a scientist or becoming a science teacher; it means creating teaching environments in which dedicated teachers have a fair chance to do a good job; and it means recognition.

Those are tough problems, but I think the country is making progress toward those goals. We're beginning to see a ground swell of public opinion and concern for the quality of education-especially for science and math. That's important because, ultimately, any lasting improvements in our educational system will have to build on stable and very broad public commitment. So the government-and the nation-is now faced with the challenge of how to capitalize on this growing momentum and how to convert it to permanent improvements in our educational system.

Now, I can't come all the way to Boston to talk to materials scientists without touching on one final topic-federal laboratories and, specifically, the National Center for Advanced Materials, or NCAM. I'll offer you one statistic that makes it clear why we've paid so much attention to the labs: One out of every six dollars spent on $\mathbf{R}$ \& D in the U.S. is spent at a federal laboratory. And that's not just one out of every six federal dollars, but one out of every six dollars total. Perhaps those people who shrug off possible reforms in the federal labs as being "just too much trouble" haven't focused on how much of the nation's R \& D resources are tied up there.

The Administration has focused on the laboratories, and especially the 12 Department of Energy national labs, because they are a public research resource of enormous potential-and we mean to put them to better use.

I admit that's easier to say than to do. These are huge institutions and it takes a great deal of patience and perseverance to change their direction. We started this effort two years ago, and we're finally beginning to sense some progress. How do I know? Well, for one reason, because the President, the Vice President, and virtually the entire Cabinet sat for a full hour listening to and discussing the results of our White House Science Council's year-long review of the federal laboratories. And within days the President had instructed the heads of the federal agencies to start implementing the review's recommendations. Without going into detail, I would summarize those recommendations as, first, insisting on a better definition of the missions of each lab; second, improving the personnel systems to attract, retain, and reward good performance by technical personnel; third, assuring stable funding rather than the roller coaster patterns of recent years; fourth, improving management and 
giving more autonomy to the labs themselves, as opposed to having the parent agencies call all the shots; and fifth, and maybe most important of all, improving the interactions among the labs and universities and industry.

I admit that the federal laboratories have been studied time and time again, but we have some special reasons for expecting significant results this time around. One reason, as I already mentioned, is the attention of the President, a man with a driving determination to use the nation's science and technology resources to shape our future. Another reason is that the review was led by David Packard, a member of my White House Science Council. Dave is truly one of the smartest industrialists in America and one whose common sense and forthright manner are extremely persuasive. More than anyone's, this is his report, and he's not going to let it set on any shelf.

\section{What We Hope to Accomplish With NCAM}

Finally, there's NCAM. Let me recap the conditions I've said we try to address with our science and technology policy, because they have a strong bearing on what we hope to accomplish with NCAM. First, materials science per se is growing in importance; additional investment will return important advances in knowledge. Second, today's research, especially applied research and engineering, increasingly requires a multidisciplinary approach. I think it's a lot more likely that the biotechnologist and the surface scientist will bump into each other in the halls of NCAM than in the university cafeteria. Third, U.S. industry, in the face of aggressive foreign competition, must be quicker off the mark in adapting new knowledge to products; that demands better interactions among scientists and engineers in three key sectors: universities, industry, and federal laboratories. And fourth, we must take better advantage of the resources of our national laboratories-remember, one-sixth of our $\mathbf{R} \&$ D spending-in addressing high-priority research problems.

Certainly one of the strengths we see for NCAM is its location-both geographic and institutional. Lawrence Berkeley Laboratory is a federal lab on the premises of one of the nation's foremost technical universities-and within an extended region of diverse, high-tech industries. As NCAM slowly evolves over the next few years, materials science there will attract broader research interest from a variety of communities. I don't think anyone can predict now just how those interactions will evolve, but we obviously think there are some important lessons to be learned along the way-lessons that we expect to be applicable to other research environments.

At this point we're focusing our attention on the development of two specific research facilities under the NCAM umbrella-the Surface Science and Catalysis Laboratory, and the Advanced Materials Laboratory. Both of these require operating space and some modest experimental facilities. Meanwhile, we'll continue to consider if more elaborate experimental facilities, such as an advanced synchrotron light source, are needed. In any case, right now our first priority is to get the two labs under way and concentrate on the cooperative research mechanisms that are central to NCAM's mission.

I do want to comment on the reaction of the materials science community to our decision to propose NCAM. I've heard from many scientists during the past year who feel that the community, using the peer review process, should be the ones to ultimately determine how available federal funds will be allocated for science. I have to differ in one important sense. Yes, the science community must have a major input to those decisions-that's how we ensure quality. That was hardly overlooked in the case of NCAM, because it was the subject of a full year's intense review in the Office of Science and Technology Policy, with considerable outside participation, before it was formally proposed in the President's budget.

I agree that peer review can be an excellent guide for how to optimize the interests of a specific discipline. But as I pointed out just a minute ago, decisions about how to use federal resources to best maintain our national $R \& D$ capability involve more than those limited perspectives. In the end, the federal $R$ \& D program has to balance many objectives in order to assure the strength of our national technology base and to make sure we're training the technical talent we'll need in future years to allow our industries to compete successfully and for our national security. The NCAM decision was made in that context.

I do hope that by now we've put to rest most of this controversy over NCAM's origins and that, guided by an external oversight group, we can proceed with the orderly development of this facility. But at the same time, why don't we try to capitalize on the interest-if not activism-that's arisen in the materials science community? This would be an excellent time for the community to address materials science's long-range needs for facilities to take advantage of new opportunities-both in basic research and in moving that research across the fuzzy boundary to the private sector.

Other communities, such as the high energy physicists and the astronomers, periodically conduct these surveys and analyses. I can assure you that the existence of an agreedupon set of priorities, generally endorsed by a research community, provides very strong guidance to someone in a job like mine. As it happens, just in the past week I've asked the President of the National Academy of Sciences, Frank Press, to initiate a review of the requirements for research facilities in materials science. We want to make sure we retain U.S. leadership across the entire spectrum of the rapidly changing area. I would certainly think this society could make important contributions to that process when it's established.

Ladies and gentlemen, let me close by simply saying once again how important I believe your work is to our nation's future. We have tried, both in our support for research and in our support for new institutions, to provide materials science with the resources it needs to build on the remarkable progress made over the past decade. We fully intend to continue that emphasis in the future. 